\title{
EFFECTS OF Electron BeAM RAdiATION ON NUTRITIONAL PARAMETERS OF Portuguese Chestnuts (Castanea Sativa Mill.)
}

Márcio Carocho $^{\mathrm{a}}$, João C.M. Barreira ${ }^{\mathrm{a}, \mathrm{b}}$, Amilcar L. Antonio ${ }^{\mathrm{a}, \mathrm{c}, \mathrm{d}}$, Albino Bento ${ }^{\mathrm{a}}$, Iwona Kaluska $^{\mathrm{e}}$, Isabel C.F.R. Ferreira, ${ }^{\mathrm{a},}$

${ }^{a}$ CIMO/Escola Superior Agrária, Instituto Politécnico de Bragança, Apartado 1172, 5301-855 Bragança, Portugal.

${ }^{\mathrm{b}}$ REQUIMTE, Departamento de Ciências Químicas, Faculdade de Farmácia da Universidade do Porto, Rua Jorge Viterbo Ferreira, 228, 4050-313 Porto, Portugal.

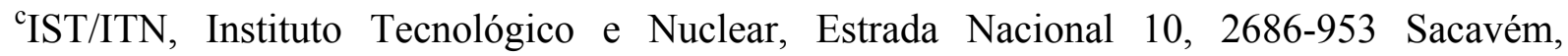
Portugal.

${ }^{\mathrm{d}}$ Departamento de Física Fundamental, Universidad de Salamanca, Plaza de la Merced, 37008 Salamanca, Spain.

${ }^{\mathrm{e}}$ Centre for Radiation Research and Technology, Institute of Nuclear Chemistry and Technology, Dorodna str. 16, 03-195 Warsaw, Poland.

* Author to whom correspondence should be addressed (e-mail: iferreira@ipb.pt telephone +351-273-303219; fax +351-273-325405).

Running title: Effects of Electron Beam on Chestnuts Nutritional Parameters 


\section{ABSTRACT}

Chestnuts are a widely consumed fruit around the world, being Portugal the fourth biggest producer in Europe. Storage of these nuts is an important step during processing, and the most widely used fumigant was banned in the European Union under the Montreal protocol due to its toxicity. Recently, radiation has been introduced as a cheap and clean conservation method. Previous studies of our research group proved that gamma radiation had no negative effect on the nutritional value of chestnuts; in fact, storage time had a much bigger influence on the chestnut quality. In the present study, we report the effect of a less ionizing radiation, electron beam, with doses of $0,0.5,1,3$ and $6 \mathrm{kGy}$ in the nutritional value of chestnuts (ash, energy, fatty acids, sugars and tocopherols), previously stored at $4{ }^{\circ} \mathrm{C}$ during 0,30 and 60 days. The storage time seemed to reduce fat and energetic values but reported a tendency for higher values of dry matter. Regarding fatty acids, there was a higher detected quantity of C20:2 in non-irradiated samples, and four fatty acids were only detected in trace quantities (C6:0; C8:0; C10:0 and C12:0). $\gamma$-tocopherol decreased during storage time but did not alter its quantity for all the radiation doses (as like $\alpha$-, $\beta$ - and $\delta$-tocopherol); in fact these compounds were present in higher concentration in the irradiated samples. Sucrose and total sugars were lower in non-irradiated samples and raffinose was only detected in irradiated samples. Electron beam irradiation seems to be a suitable methodology, since the effects on chemical and nutritional composition are very low, while storage time seems to be quite important in chestnut deterioration.

KEYWORDS: Irradiation; Electron beam; Chestnuts; Nutrients; Storage time 


\section{INTRODUCTION}

Chestnuts are one of the oldest consumed fruits in Portugal; they were consumed many centuries before potatoes and other tubers became available. ${ }^{1}$ Recently, the land occupied with chestnut trees in Europe rose from 81,511 ha (2005) to 87,521 ha (2008). ${ }^{2}$ The Trás-osMontes region, in the northeastern part of Portugal, produces $75 \%$ of the nation's chestnuts, being one of the region's main economic resources. Chestnuts consumption could be stimulated due to their antioxidant potential ${ }^{3-5}$ and health benefits derived from compounds such as tocopherols and polyunsaturated fatty acids that have been found in these nuts, ${ }^{6,7}$ being described as effective against cancer, atherosclerosis, myocardial infarction among many other diseases. ${ }^{8,9}$ Our research group has already studied the nutritional value of chestnuts, determining that the major fatty acids were linoleic, linolenic and palmitic acids, ${ }^{10}$ $\gamma$-tocopherol was the most predominant tocopherol, ${ }^{6}$ while sucrose was the principal sugar. ${ }^{7}$ Although chestnuts may seem dry, they are perishable, and have a limited shelf-life, due to their high metabolic activity. ${ }^{11}$ Also, during harvest period they could became infested with two type insects (Curculio elephas Gyllenhal and Cydia splendana Hübner) that cause losses for the producers and for industry and since a significant part of the production is to export, it must also fulfill the international phytosanitary regulations, eliminating the presence of insects. Until 2010 the most common disinfestation method (elimination of insects) was methyl bromide, but under the Montreal Protocol guidelines, the European Union restricted its use for allegedly being toxic to the operators and polluting the environment. ${ }^{12}$ There are several alternative disinfestation methods like temperature treatment, cold or hot water dip, as well as other fumigants, ${ }^{13}$ but they still represent quite a number of limitations and disadvantages.

Recently, irradiation has become a promising alternative for chestnut conservation and disinfestation, especially in Korea, where these nuts are irradiated with a maximum of 0.25 
kGy for sprout inhibition and with $0.50 \mathrm{kGy}$ for insects disinfestations. ${ }^{14,15}$ Some research groups are trying different types of radiation with different doses to guarantee pest free chestnuts. Our research group has tested both low doses of gamma radiation $(0.27$ and 0.54 $\mathrm{kGy})^{16}$ and higher doses ( 1 and $\left.3 \mathrm{kGy}\right),{ }^{17}$ being concluded that none of the doses altered the nutritional value of chestnuts. There are available reports regarding the use of electron beam radiation on chestnuts to kill Curculio sikkimensis larvae ${ }^{18}$ and to destroy yeasts and moulds, ${ }^{19}$ nevertheless, nothing is known regarding the effects of electron beam radiation on the nutritional parameters of these nuts. Herein, we report the effects of different doses (0control, $0.5,1,3$ and $6 \mathrm{kGy})$ of electron beam radiation and different storage periods (0assays conducted immediately after irradiation, 30 and 60 days) on nutritional value of chestnuts and their sugars, fatty acids and tocopherols composition.

\section{MATERIALS AND METHODS}

\section{Standards and Reagents}

Acetonitrile $99.9 \%$, n-hexane $95 \%$ and ethyl acetate $99.8 \%$ were of HPLC grade, and purchased from Lab-Scan (Lisbon, Portugal). The fatty acids methyl ester (FAME) reference standard mixture 37 (standard 47885-U) was purchased from Sigma (St. Louis, Missouri, USA), as well as the other individual fatty acid isomers, tocopherols $(\alpha-, \beta-, \gamma-$, and $\delta$ isoforms) and sugars (D(-)-fructose, $\mathrm{D}(+)$-glucose anhydrous, $\mathrm{D}(+)$-raffinose pentahydrate, $\mathrm{D}(+)$-sucrose, $\mathrm{D}(+)$-trehalose) standards. Racemic tocol, $50 \mathrm{mg} / \mathrm{mL}$, was purchased from Matreya (Pennsylvania, USA). All other chemicals and solvents were of analytical grade and purchased from common sources. Water was treated in a Milli-Q water purification system (TGI Pure Water Systems, South Carolina, USA). 


\section{Samples and Samples Irradiation}

Chestnut samples were obtained in an industrial unit (Agroaguiar Lda.) of Trás-os-Montes, Northeastern Portugal. The irradiation was performed at the INCT - Institute of Nuclear Chemistry and Technology - in Warsaw, Poland. The samples were divided into five groups: control (without irradiation); sample 1 (0.5 kGy), sample 2 (1 kGy), sample 3 (3 kGy) and sample 4 (6 kGy) with fifteen units per group. To estimate the dose during the irradiation process three types of dosimeters were used, a standard dosimeter, a graphite calorimeter, and two routine Gammachrome YR and Amber Perspex dosimeters, from Harwell company (U.K.). The irradiation took place in a e-beam irradiator of $10 \mathrm{MeV}$ of energy with a pulse duration of $5.5 \mu \mathrm{s}$, a pulse frequency of $440 \mathrm{~Hz}$, the average beam current was $1.1 \mathrm{~mA}$, the scan width of $68 \mathrm{~cm}$, the conveyer speed in the range $20-100 \mathrm{~cm} / \mathrm{min}$ and a scan frequency of $5 \mathrm{~Hz}$. The absorbed dose was $0.53,0.83,2.91 \mathrm{kGy}$ and $6.10 \mathrm{kGy}$, with an uncertainty of $20 \%$ for the two first doses, $15 \%$ for the third dose and $10 \%$ for the last dose. To read the Amber and Gammachrome YR dosimeters, spectrophotometric methods were used. For the Graphite calorimeter dosimeter the electrical resistance was read and converted in dose according to a previous calibrated curve. For simplicity, from now on we refer only the exact value for the dose: $0,0.5,1,3$ and $6 \mathrm{kGy}$.

From each group, three subgroups with five units were randomly selected. Subgroup 1 was promptly analysed, subgroup 2 was stored at $4{ }^{\circ} \mathrm{C}$ (refrigerator) for 30 days and subgroup 3 was stored in the same conditions for 60 days (period enough for collection, storage, calibration and export to final destination until further use). Prior to analysis, all the samples were lyophilized (FreeZone 4.5 model 7750031, Labconco, Kansas, USA), reduced to a fine dried powder (20 mesh) and mixed to obtain homogenate samples.

\section{Energetic Value}


The samples were analysed for proximate composition (dry matter, proteins, fat, carbohydrates and ash) using the AOAC procedures. ${ }^{20}$ The crude protein content of the samples was estimated by the macro-Kjeldahl method; the crude fat was determined by extracting a known weight of powdered sample with petroleum ether, using a Soxhlet apparatus; the ash content was determined by incineration at $600 \pm 15^{\circ} \mathrm{C}$. Total carbohydrates were calculated by difference. Total energy was calculated according to the following equations: Energy $(\mathrm{kcal})=4 \times(\mathrm{g}$ proteins $+\mathrm{g}$ carbohydrates $)+9 \times(\mathrm{g}$ fat $)$.

\section{Analysis of Free Sugars}

Free sugars were determined by high performance liquid chromatography coupled to a refraction index detector (HPLC-RI) as described previously by the authors. ${ }^{7}$ The equipment consisted of an integrated system with a pump (Knauer, Smartline system 1000), degasser system (Smartline manager 5000), auto-sampler (AS-2057 Jasco) and a RI detector (Knauer Smartline 2300). The data was analysed using Clarity 2.4 Software (DataApex). The chromatographic separation was achieved with a Eurospher 100-5 NH2 column $(4.6$ x 250 $\mathrm{mm}, 5 \mathrm{~mm}$, Knauer) operating at $30{ }^{\circ} \mathrm{C}$ (7971 R Grace oven). The mobile phase was acetonitrile/deionized water, 7:3 (v/v) at a flow rate of $1 \mathrm{ml} / \mathrm{min}$. The identification was made by comparing the relative retention times of sample peaks with standards. Quantification was made by the internal standard method and the results are expressed in $\mathrm{g}$ per $100 \mathrm{~g}$ of dry weight (dw).

\section{Analysis of Fatty Acids}

Fatty acids were determined by gas-liquid chromatography with flame ionization detection (GC-FID)/capillary column as described previously by the authors. ${ }^{16}$ The equipment was a GC 1000 (DANI) with a split/splitless injector, a FID and a Macherey-Nagel column (30 m × 
$0.32 \mathrm{~mm}$ ID $\times 0.25 \mu \mathrm{m} \mathrm{df})$. The oven temperature program was as follows: the initial temperature of the column was $50{ }^{\circ} \mathrm{C}$, held for $2 \mathrm{~min}$, then a $30{ }^{\circ} \mathrm{C} / \mathrm{min}$ ramp to $125^{\circ} \mathrm{C}, 5$ ${ }^{\circ} \mathrm{C} / \mathrm{min}$ ramp to $160{ }^{\circ} \mathrm{C}, 20{ }^{\circ} \mathrm{C} / \mathrm{min}$ ramp to $180{ }^{\circ} \mathrm{C}, 3{ }^{\circ} \mathrm{C} / \mathrm{min}$ ramp to $200{ }^{\circ} \mathrm{C}, 20{ }^{\circ} \mathrm{C} / \mathrm{min}$ ramp to $220{ }^{\circ} \mathrm{C}$ and held for $15 \mathrm{~min}$. The carrier gas (hydrogen) flow-rate was $4.0 \mathrm{ml} / \mathrm{min}(0.61$ bar), measured at $50{ }^{\circ} \mathrm{C}$. Split injection (1:40) was carried out at $250{ }^{\circ} \mathrm{C}$. Fatty acid identification was made by comparing the relative retention times of FAME peaks from samples with standards. The results were recorded and processed using CSW 1.7 software (DataApex 1.7) and expressed in relative percentage of each fatty acid.

\section{Analysis of Tocopherols}

Tocopherols content was determined following a procedure previously described by the authors. ${ }^{16}$ The HPLC system described above was connected to a fluorescence detector (FP2020; Jasco) programmed for excitation at $290 \mathrm{~nm}$ and emission at $330 \mathrm{~nm}$. The chromatographic separation was achieved with a Polyamide II $(250 \times 4.6 \mathrm{~mm})$ normal-phase column from YMC Waters operating at $30{ }^{\circ} \mathrm{C}$. The mobile phase used was a mixture of $\mathrm{n}$ hexane and ethyl acetate $(70: 30, \mathrm{v} / \mathrm{v})$ at a flow rate of $1 \mathrm{ml} / \mathrm{min}$. The compounds were identified by chromatographic comparisons with authentic standards. Quantification was based on the fluorescence signal response, using the internal standard method. Tocopherol contents in the samples are expressed in mg per $100 \mathrm{~g}$ of dry weight (dw).

\section{Statistical Analysis}

For each one of the storage times and irradiation doses three samples were analysed, with all the assays being also carried out in triplicate. An analysis of variance (ANOVA) with Type III sums of squares was performed using the GLM (General Linear Model) procedure of the SPSS software, version 18.0. The dependent variables were analyzed using 2-way ANOVA, 
with the main factors "irradiation dose" (ID) and "storage time" (ST). When a (ID $\times$ ST) was detected, the two factors were evaluated simultaneously by the estimated marginal means plots for all levels of each single factor. Alternatively, if no statistical significant interaction was verified, means were compared using Tukey's honestly significant difference (HSD) multiple comparison test.

In addition, a linear discriminant analysis (LDA) was used to assess the influence of either different storage times or irradiation doses on proximate composition, fatty acids, tocopherols or sugars profiles. A stepwise technique, using the Wilks' $\lambda$ method with the usual probabilities of F (3.84 to enter and 2.71 to remove), was applied for variable selection. This procedure uses a combination of forward selection and backward elimination procedures, where before selecting a new variable to be included, it is verified whether all variables previously selected remain significant. ${ }^{21,22}$ With this approach, it is possible to identify the significant variables obtained for each sample. To verify which canonical discriminant functions were significant, the Wilks' $\lambda$ test was applied. A leaving-one-out cross-validation procedure was carried out to assess the model performance.

All statistical tests were performed at a 5\% significance level. All the assays were carried out in triplicate. The results are expressed as mean values with standard deviation (SD).

\section{RESULTS AND DISCUSSION}

The effects of electron beam irradiation $(0,0.5,1,3$ and $6 \mathrm{kGy})$ and storage time $(0,30$ and 60 days), as well as the interaction of both effects, were assessed by evaluating changes in nutritional composition of selected chestnut samples. Considering both effects together, it is possible to understand the influence of irradiation dose (ID) independently of storage time (ST) and vice versa, an essential requirement to consider electron beam irradiation as a feasible conservation technique. 
Table 1 shows the proximate composition and energetic value data reported as mean value of each ID along the different storage times, as well as mean value of each ST for the five irradiation doses. ST $\times$ ID interaction was a significant $(P<0.05)$ source of variation for dry matter, protein and carbohydrates. Among the remaining parameters, the effect of each individual main factor was only significant for fat content (in both cases) and energy value (only for ST). The allowed multiple comparisons pointed out a lower fat content and energy value after 60 days of storage, while the highest content of fat was quantified in samples irradiated with a $3 \mathrm{kGy}$ irradiation dose (ID). However, from the analysis of the plots (data not shown) of the estimated margins means (EMM), it was also possible to identify a marked tendency for a higher dry matter value after 60 days of storage.

Table 2 shows the fatty acids composition data reported as mean value of each ID along the different storage times, as well as mean value of ST for the five irradiation doses. Following the same reasoning, the multiple comparisons could only be performed on C17:0 (higher for 0 days), C20:0 (higher for 0 days) and C23:0 (higher for 0 days and for $1 \mathrm{kGy}$ ). The plots (data not included) of the EMM also showed an increased value for C20:2 in the non-stored samples. Besides the sixteen tabled fatty acids, four more (C6:0, C8:0, C10:0, C12:0) were quantified in trace $(<0.10 \%)$ quantities.

The results obtained for tocopherols profile indicate a significant decrease in $\gamma$-tocopherol contents along ST (Table 3; Figure 1 A), which is in agreement with previous results in chestnuts submitted to gamma irradiation (another type of radiation). ${ }^{17}$ The applied ID did not cause any significant change in tocopherol profiles, but the overall content tended to be higher in irradiated samples (Figure 1B). In another study, ${ }^{16}$ the use of gamma irradiation exerted a protective effect on vitamin E content that could be associated with the conversion of molecular to atomic oxygen, decreasing the oxidation of tocopherol molecules. Furthermore, vitamin E has a well-known stabilizing effect against oxidation. ${ }^{23}$ 
The results obtained for individual sugars are presented in Table 4. Like the former results, ST caused higher changes than ID, despite the only statistical significant differences that might be pointed out were the lower values obtained for sucrose and total sugars in non stored samples. Furthermore, raffinose was only found in non stored samples, indicating that the trisaccharide might have been hydrolyzed along time; this hypothesis is reinforced by the slight increase of fructose and glucose, despite galactose had not been detected.

In general, the results are similar to those obtained in previous studies, ${ }^{1,6,10,24-26}$ with water and carbohydrates as major components among nutritional parameters, oleic and linoleic acids as the main fatty acids, $\gamma$-tocopherol as the most abundant vitamin $\mathrm{E}$ isoform and sucrose as the highest individual sugar.

Generally, the assayed electron beam ID (0.5 to $6 \mathrm{kGy})$ seemed to produce less obvious effects than ST in all the assessed parameters.

To confirm this assumption, the results were evaluated through a linear discriminant analysis (LDA). All independent variables selected by the stepwise procedure of the discriminant analysis were statistically significant according to the Wilks' $\lambda$ test $(P<0.05)$.

The LDA was performed according with the analysed groups of compounds (proximate composition, fatty acids, tocopherols or individual sugars, or all parameters simultaneously), in order to find which one permitted the best classification performance. The main outcomes for each case are presented in Table 5. As it can be seen, the differences induced by ID showed higher discriminant ability than those caused by ST. When the results of all assayed parameters were included in the model, $96.7 \%$ of the cases were correctly classified; i.e. the differences verified among non stored samples, samples stored for 30 days or samples stored for 60 days, were sufficient to separate the obtained values in distinct groups. In fact only three of the ninety assayed cases were misclassified (3 non stored samples were classified as having been stored for 30 days). The two defined functions (Figure 2) included $100.0 \%$ of the 
observed variance, with the first function separating 0 days and 30 days from 60 days (means of the canonical variance $(\mathrm{MCV})$ : 0 days $=-0.458,30$ days $=-2.176$ and 60 days $=4.635$, mostly based on C10:0 and dry matter contents. The second function allowed the separation of 0 and 30 days storage times (MCV: 0 days $=2.044,30$ days $=-2.128$ and 60 days $=0.085$, showing a high correlation with raffinose contents. The model showed a very satisfactory classification performance allowing to correctly classifying $97.0 \%$ of the samples for the original groups and $96.3 \%$ for the cross-validation procedure. As it had already been verified $^{27}$ fatty acid profiles are important to evaluate differences induced by ST in chestnut samples, since 5 of the 8 selected variables in the analysis were fatty acids.

The LDA results in Table 5 highlighted the low discriminant ability of ID. Even with all parameters, the classification performance reached only $36.7 \%$, the same value as the obtained for the analysis based only on fatty acids profile. In the case of nutritional and sugars profiles, none variable was qualified for the analysis, proving the high similarity among the results obtained for different ST.

Overall, either considering the effect of ST or ID, the number of correctly classified cases in the LDA for fatty acids, tocopherols, sugars or nutritional parameters was not as high as in previous works dealing with the application of gamma irradiation as an alternative conservation methodology. ${ }^{16,17,27}$ So, in this particular subject, electron beam irradiation seems to be a more adequate methodology, since the effects on chemical and nutritional composition were less detectable that those caused by gamma irradiation. However, it is mandatory to perform further studies (for instance, biocide efficacy or food safety requirements) to consider its application as a useful alternative.

\section{ACKNOWLEDGEMENTS}


The authors thank ON.2/QREN/EU Project no.13198/2010 for financial support of this work, to Fundação para a Ciência e a Tecnologia (FCT, Portugal) and COMPETE/QREN/EU for financial support to CIMO (strategic project PEst-OE/AGR/UI0690/2011). A.L. Antonio and J.C.M. Barreira also thank to FCT, POPH-QREN and FSE for their grants (SFRH/PROTEC/67398/2010 and SFRH/BPD/72802/2010, respectively). Prof. A. Chmielewski, General Director of the Institute of Nuclear Chemistry and Technology, Warsaw, Poland, for allowing e-beam irradiations.

\section{References}

(1) Borges, O.P.; Carvalho, J.S.; Correia, P.R.; Silva, A.P. Lipid and fatty acid of profiles of Castanea sativa Mill. chestnuts of 17 native Portuguese cultivars. J. Food Compos. Anal. 2007, 20, 80-89.

(2) FAOSTAT, Food and Agriculture Organization of the United Nations, 2010. Available from: <http://faostat.fao.org/site/339/default.aspx >

(3) Barreira, J.C.M.; Ferreira, I.C.F.R.; Oliveira, M.B.P.P.; Pereira, J.A. Antioxidant activities of the extracts from chestnut flower, leaf, skins and fruit. Food Chem. 2008, 107, 1106-1113.

(4) Neri, L.; Dimitri, G.; Sacchetti, G. Chemical composition and antioxidant activity of cured chestnuts from three sweet chestnuts (Castanea sativa Mil.) ecotypes from Italy. J. Food Comp. Anal. 2010, 23, 23-29.

(5) Dinis, L.T.; Oliveira, M.M.; Almeida, J.; Costa, R.; Gomes-Laranjo, J.; Peixoto, F. Antioxidant activities of Chestnut nut of Castanea sativa Mill. (cultivar "Judia") as function of origin ecosystem. Food Chem. 2012, 132, 1-8. 
(6) Barreira, J.C.M.; Alves, R.C.; Casal, S.; Ferreira, I.C.F.R.; Oliveira, M.B.P.P.; Pereira, J.A. Vitamin E profile as a reliable authenticity discrimination factor between chestnut (Castanea sativa) cultivars. J. Agric. Food Chem. 2009, 57, 5524-5528.

(7) Barreira, J.C.M.; Pereira, J.A.; Oliveira, M.B.P.P.; Ferreira, I.C.F.R. Sugar profiles of different chestnuts (Castanea sativa Mill.) and almond (Prunus dulcis) cultivars by HPLC-RI. Plant Food. Human Nutr. 2010, 65, 38-43.

(8) Benatti, P.; Peluso, G.; Nicolai, R.; Calvani, M. Polyunsaturated fatty acids: Biochemical, nutritional and epigenic properties. J. Am. Coll. Nutr. 2004, 4, 281-302.

(9) Hensley, K.; Benaksas, E.J.; Bolli, R.; Comp, P.; Grammas, P.; Hamdheydari, L.; Mou, S.; Pye, Q.N.; Stoddard, M.F.; Wallis, G.; Williamson, K.S.; West, M.; Wechter, W.J.; Floyd, R.A. New perspectives on vitamin E: $\gamma$-tocopherol and carboxyethylhydroxychroman metabolites in biology and medicine. Free Rad. Biol. Med. 2004, 36, 1-15.

(10) Barreira, J.C.M.; Alves, R.C.; Casal, S.; Ferreira, I.C.F.R.; Oliveira, M.B.P.P.; Pereira, J.A. Nutritional, fatty acid and triacylglycerol profiles of Castanea sativa Mill. Cultivars: A compositional and chemometric approach. J. Agric. Food Chem. 2009, $57,2836-2842$.

(11) Correia, P.; Leitão, A.; Beirão-da-Costa, M.L. The effect of drying temperatures on morphological and chemical properties of dried chestnuts flours. J. Food Eng. 2009, 90, 325-332.

(12) Official Journal of the European Union, 2008. Commission Decision, 753/2008, 2609-2008.

(13) Fields, P.G.; White, N.D.G. Alternatives to methyl bromide treatments for storedproduct and quarantine insects. Ann. Rev.Entomol. 2002, 47, 331-359. 
(14) Chung, H.; Delincée, H.; Han, S.; Hong, J.; Kim, H.; Kim, M.; Byun, M.; Kwon, J. Trials to identify irradiated chestnut (Castanea bungena) with different analytical techniques. Rad. Phys. Chem. 2004, 71, 179-182.

(15) Kwon, J.-H.; Kwon, Y.-J.; Byun, M.-W.; Kim, K.-S. Competitiveness of gamma irradiation with fumigation for chestnuts associated with quarantine and quality security. Rad. Phys. Chem. 2004, 71, 41-44.

(16) Fernandes, Â.; Antonio, A.L.; Barros, L; Barreira, J.C.M.; Bento, A.; Botelho, M.L.; Ferreira, I.C.F.R. Low dose $\gamma$-irradiation as a suitable solution for chestnut (Castanea sativa Miller) conservation: Effects on sugars, fatty acids and tocopherols. J. Agric. Food Chem. 2011, 59, 10028-10033.

(17) Fernandes, Â.; Barreira, J.C.M.; Antonio, A.L.; Bento, A.; Botelho, M.L.; Ferreira, I.C.F.R. Assessing the effects of gamma radiation and storage time in energetic value and major individual nutrients of chestnuts. Food Chem. Toxicol. 2011, 49, 24292432.

(18) Todoriki, S.; Hasan, M.; Miyanoshita, A.; Imamura, T.; Hayashi, T. Assessment of electron beam-induced DNA damage in larvae of chestnut weevil, Curculio sikkimensis (Heller) (Coleoptera: Curculionidae) using comet assay. Rad. Phys. Chem. 2006, 75, 292-296.

(19) Erhan, I.; Bala, K.; Joseph, M.; Suresh,P. Electron beam radiation of dried fruits and nuts to reduce yeast and mould bioburden. J. Food Protec. 2007, 70, 981-985.

(20) AOAC. 1995. Official methods of analysis (16th Ed.). Arlington VA, USA: Association of Official Analytical Chemists.

(21) Maroco, J. Análise Estatística, com utilização do SPSS, 2003, Edições Sílabo, Lisboa, Portugal. 
(22) López, A.; García, P.; Garrido, A. Multivariate characterization of table olives according to their mineral nutrient composition. Food Chem. 2008, 106, 369-378.

(23) Bracco, P.; Brunella, V.; Zanetti, M.; Luda, M.P.; Costa, L. Stabilisation of ultra-high molecular weight polyethylene with Vitamin E. Polym. Degrad. Stability, 2007, 92, $2155-2162$.

(24) Borges, O.; Gonçalves, B.; Carvalho, J.L.S.; Correia, P.; Silva, A.P. Nutritional quality of Chestnut (Castanea sativa Mill.) cultivars from Portugal. Food Chem. 2008, 106, 976-984.

(25) Vasconcelos, M.C.M.B.; Bennet, R.N.; Rosa, E.A.S.; Cardoso, J.V.F. Primary and secondary metabolite composition of kernels from three cultivars of Portuguese chestnut (Castanea sativa Mill.) at different stages of industrial transformation. $J$. Agric. Food Chem. 2007, 55, 3508-3516.

(26) Vasconcelos, M.C.B.M.; Bennett, R.N.; Rosa, E.A.S.; Ferreira-Cardoso, J.V. Composition of European chestnut (Castanea sativa Mill.) and association with health effects: fresh and processed products. J. Sci. Food Agric. 2010, 90, 1578-1589.

(27) Barreira, J.C.M.; Antonio, A.L.; Günaydi, T.; Alkan, H.; Bento, A.; Botelho, M.L.; Ferreira, I.C.F.R. Chemometric characterization of gamma irradiated chestnuts from Turkey. Rad. Phys. Chem. 2012, in press. 
Table 1. Chestnuts nutritional parameters and energetic values according with irradiation dose (ID) and storage time (ST) (mean \pm SD).

\begin{tabular}{|c|c|c|c|c|c|c|c|}
\hline & & $\begin{array}{l}\text { Dry matter } \\
\text { (g/ } 100 \mathrm{~g} \mathrm{fw})\end{array}$ & $\begin{array}{c}\text { Fat } \\
(\mathrm{g} / 100 \mathrm{~g} \mathrm{dw})\end{array}$ & $\begin{array}{c}\text { Protein } \\
(\mathrm{g} / 100 \mathrm{~g} \mathrm{dw})\end{array}$ & $\begin{array}{c}\text { Ash } \\
(\mathrm{g} / 100 \mathrm{~g} \mathrm{dw})\end{array}$ & $\begin{array}{l}\text { Carbohydrates } \\
(\mathrm{mg} / 100 \mathrm{~g} \mathrm{dw})\end{array}$ & $\begin{array}{c}\text { Energy } \\
(\mathrm{kcal} / 100 \mathrm{~g} \mathrm{dw})\end{array}$ \\
\hline \multirow{4}{*}{ ST } & 0 days & $58 \pm 3$ & $3 \pm 1 \mathrm{a}$ & $6 \pm 2$ & $1.8 \pm 0.4$ & $89 \pm 2$ & $409 \pm 4 \mathrm{a}$ \\
\hline & 30 days & $56 \pm 5$ & $3 \pm 1 \mathrm{a}$ & $6 \pm 2$ & $2 \pm 3$ & $89 \pm 3$ & $408 \pm 12 \mathrm{ab}$ \\
\hline & 60 days & $71 \pm 5$ & $2 \pm 1 \mathrm{~b}$ & $5 \pm 2$ & $2.0 \pm 0.3$ & $91 \pm 2$ & $404 \pm 4 b$ \\
\hline & $P$-value $(\mathrm{n}=45)$ & $<0.001$ & $<0.001$ & 0.050 & 0.949 & 0.003 & 0.012 \\
\hline \multirow{6}{*}{ ID } & $0 \mathrm{kGy}$ & $63 \pm 7$ & $2.7 \pm 0.5 \mathrm{~b}$ & $5 \pm 2$ & $1.8 \pm 0.5$ & $90 \pm 2$ & $407 \pm 4$ \\
\hline & $0.5 \mathrm{kGy}$ & $62 \pm 9$ & $2.8 \pm 0.4 \mathrm{~b}$ & $5 \pm 2$ & $1.7 \pm 0.5$ & $90 \pm 2$ & $407 \pm 6$ \\
\hline & $1 \mathrm{kGy}$ & $63 \pm 6$ & $3.0 \pm 0.5 \mathrm{ab}$ & $5 \pm 2$ & $1.9 \pm 0.3$ & $90 \pm 2$ & $408 \pm 4$ \\
\hline & $3 \mathrm{kGy}$ & $60 \pm 7$ & $3.4 \pm 0.5 \mathrm{a}$ & $5 \pm 2$ & $3 \pm 4$ & $89 \pm 4$ & $406 \pm 15$ \\
\hline & $6 \mathrm{kGy}$ & $60 \pm 10$ & $2.8 \pm 0.5 \mathrm{~b}$ & $5 \pm 2$ & $1.6 \pm 0.3$ & $90 \pm 2$ & $408 \pm 5$ \\
\hline & $P$-value $(\mathrm{n}=27)$ & 0.144 & 0.011 & 0.973 & 0.351 & 0.391 & 0.983 \\
\hline $\mathrm{ST} \times \mathrm{I}$ & $P$-value & 0.021 & 0.060 & 0.023 & 0.385 & 0.033 & 0.478 \\
\hline
\end{tabular}

Results are reported as mean value of each irradiation dose (ID) over the different storage times (ST) as well as mean value of all ST within each

ID. Therefore, SD reflects values in those samples (under different ID or ST). In each column, different letters mean significant differences. 
Table 2. Fatty acids profiles (percentage) according with ID and ST (mean \pm SD).

\begin{tabular}{|c|c|c|c|c|c|c|c|c|c|c|c|}
\hline \multirow{2}{*}{ Compound } & \multicolumn{4}{|c|}{ ST } & \multicolumn{6}{|c|}{ ID } & \multirow{2}{*}{$\begin{array}{l}\mathrm{ST} \times \mathrm{ID} \\
P \text {-value }\end{array}$} \\
\hline & 0 days & 30 days & 60 days & $P$-value $(\mathrm{n}=45)$ & $0 \mathrm{kGy}$ & $0.5 \mathrm{kGy}$ & $1 \mathrm{kGy}$ & $3 \mathrm{kGy}$ & $6 \mathrm{kGy}$ & $P$-value $(\mathrm{n}=27)$ & \\
\hline C14:0 & $0.14 \pm 0.05$ & $0.14 \pm 0.03$ & $0.14 \pm 0.02$ & 0.877 & $0.14 \pm 0.03$ & $0.15 \pm 0.04$ & $0.14 \pm 0.05$ & $0.13 \pm 0.06$ & $0.15 \pm 0.02$ & 0.349 & 0.052 \\
\hline C15:0 & $0.09 \pm 0.02$ & $0.09 \pm 0.01$ & $0.09 \pm 0.01$ & 0.129 & $0.09 \pm 0.01$ & $0.10 \pm 0.02$ & $0.09 \pm 0.01$ & $0.08 \pm 0.01$ & $0.09 \pm 0.01$ & 0.025 & 0.002 \\
\hline C16:0 & $17 \pm 3$ & $16 \pm 1$ & $16 \pm 1$ & 0.015 & $16 \pm 1$ & $16 \pm 1$ & $17 \pm 3$ & $17 \pm 2$ & $17 \pm 2$ & 0.132 & $<0.001$ \\
\hline C16:1 & $0.3 \pm 0.1$ & $0.35 \pm 0.05$ & $0.4 \pm 0.1$ & $<0.001$ & $0.3 \pm 0.1$ & $0.39 \pm 0.05$ & $0.3 \pm 0.1$ & $0.3 \pm 0.1$ & $0.4 \pm 0.1$ & 0.003 & 0.009 \\
\hline $\mathrm{C} 17: 0$ & $0.16 \pm 0.02 \mathrm{a}$ & $0.14 \pm 0.01 \mathrm{~b}$ & $0.14 \pm 0.01 \mathrm{~b}$ & $<0.001$ & $0.14 \pm 0.01$ & $0.14 \pm 0.02$ & $0.15 \pm 0.03$ & $0.15 \pm 0.03$ & $0.14 \pm 0.02$ & 0.086 & 0.118 \\
\hline C18:0 & $1.1 \pm 0.3$ & $1.0 \pm 0.1$ & $1.0 \pm 0.1$ & 0.054 & $1.1 \pm 0.1$ & $1.0 \pm 0.1$ & $1.0 \pm 0.2$ & $1.1 \pm 0.3$ & $1.1 \pm 0.2$ & 0.727 & 0.261 \\
\hline C18:1 & $33 \pm 5$ & $31 \pm 5$ & $32 \pm 3$ & 0.045 & $32 \pm 2$ & $31 \pm 5$ & $32 \pm 3$ & $34 \pm 3$ & $30 \pm 6$ & 0.009 & $<0.001$ \\
\hline C18:2 & $41 \pm 5$ & $44 \pm 3$ & $43 \pm 3$ & $<0.001$ & $43 \pm 2$ & $43 \pm 3$ & $42 \pm 5$ & $40 \pm 3$ & $44 \pm 5$ & 0.028 & $<0.001$ \\
\hline C18:3 & $5 \pm 2$ & $6 \pm 1$ & $6 \pm 1$ & 0.545 & $6 \pm 1$ & $6 \pm 1$ & $5 \pm 1$ & $5 \pm 1$ & $6 \pm 1$ & 0.014 & 0.027 \\
\hline $\mathrm{C} 20: 0$ & $0.5 \pm .02 \mathrm{a}$ & $0.38 \pm 0.04 \mathrm{~b}$ & $0.40 \pm 0.04 \mathrm{ab}$ & 0.017 & $0.39 \pm 0.05$ & $0.40 \pm 0.04$ & $0.5 \pm 0.3$ & $0.4 \pm 0.1$ & $0.4 \pm 0.1$ & 0.323 & 0.146 \\
\hline C20:1 & $0.6 \pm 0.3$ & $0.6 \pm 0.1$ & $0.6 \pm 0.1$ & 0.457 & $0.64 \pm 0.05$ & $0.6 \pm 0.1$ & $0.6 \pm 0.3$ & $0.6 \pm 0.2$ & $0.6 \pm 0.2$ & 0.657 & 0.560 \\
\hline C20:2 & $0.1 \pm 0.1$ & $0.03 \pm 0.01$ & $0.03 \pm 0.01$ & $<0.001$ & $0.03 \pm 0.01$ & $0.03 \pm 0.01$ & $0.1 \pm 0.1$ & $0.1 \pm 0.1$ & $0.05 \pm 0.03$ & 0.046 & 0.027 \\
\hline $\mathrm{C} 20: 3$ & $0.1 \pm 0.1$ & $0.06 \pm 0.01$ & $0.06 \pm 0.01$ & 0.015 & $0.06 \pm 0.01$ & $0.06 \pm 0.01$ & $0.1 \pm 0.1$ & $0.06 \pm 0.01$ & $0.07 \pm 0.01$ & 0.003 & 0.007 \\
\hline $\mathrm{C} 22: 0$ & $0.3 \pm 0.1$ & $0.28 \pm 0.04$ & $0.30 \pm 0.05$ & 0.566 & $0.28 \pm 0.05$ & $0.30 \pm 0.04$ & $0.3 \pm 0.1$ & $0.29 \pm 0.05$ & $0.31 \pm 0.05$ & 0.484 & 0.101 \\
\hline $\mathrm{C} 23: 0$ & $0.08 \pm 0.02 \mathrm{a}$ & $0.07 \pm 0.01 \mathrm{~b}$ & $0.07 \pm 0.01 \mathrm{ab}$ & 0.043 & $0.07 \pm 0.01 \mathrm{~b}$ & $0.08 \pm 0.01 \mathrm{ab}$ & $0.09 \pm 0.02 \mathrm{a}$ & $0.07 \pm 0.02 \mathrm{~b}$ & $0.07 \pm 0.01 \mathrm{ab}$ & 0.012 & 0.286 \\
\hline $\mathrm{C} 24: 0$ & $0.16 \pm 0.04$ & $0.15 \pm 0.02$ & $0.16 \pm 0.03$ & 0.331 & $0.15 \pm 0.03$ & $0.16 \pm 0.03$ & $0.16 \pm 0.04$ & $0.15 \pm 0.03$ & $0.16 \pm 0.03$ & 0.646 & 0.474 \\
\hline SFA & $20 \pm 3$ & $18 \pm 1$ & $19 \pm 1$ & 0.006 & $18 \pm 2$ & $19 \pm 1$ & $19 \pm 4$ & $19 \pm 2$ & $20 \pm 2$ & 0.186 & 0.001 \\
\hline MUFA & $34 \pm 5$ & $32 \pm 5$ & $33 \pm 2$ & 0.054 & $33 \pm 2$ & $32 \pm 4$ & $33 \pm 3$ & $35 \pm 3$ & $31 \pm 6$ & 0.009 & $<0.001$ \\
\hline PUFA & $46 \pm 6$ & $50 \pm 4$ & $49 \pm 3$ & 0.001 & $49 \pm 2$ & $50 \pm 4$ & $48 \pm 6$ & $46 \pm 3$ & $49 \pm 6$ & 0.007 & $<0.001$ \\
\hline
\end{tabular}

Results are reported as mean value of each irradiation dose (ID) over the different storage times (ST) as well as mean value of all ST within each

ID. Therefore, SD reflects values in those samples (under different ID or ST). In each column, different letters mean significant differences. 
Table 3. Composition in tocopherols $(\mu \mathrm{g} / 100 \mathrm{~g} d w)$ according with ID and ST (mean \pm SD).

\begin{tabular}{|c|c|c|c|c|c|}
\hline & & $\alpha$-Tocopherol & $\gamma$-Tocopherol & $\delta$-Tocopherol & Total \\
\hline \multirow{4}{*}{ ST } & 0 days & $2 \pm 2$ & $1192 \pm 185 \mathrm{a}$ & $19 \pm 11$ & $1213 \pm 190 \mathrm{a}$ \\
\hline & 30 days & $2 \pm 1$ & $1149 \pm 262 \mathrm{a}$ & $37 \pm 61$ & $1187 \pm 255 \mathrm{a}$ \\
\hline & 60 days & $1.6 \pm 0.5$ & $825 \pm 224 b$ & $23 \pm 17$ & $850 \pm 229 b$ \\
\hline & $P$-value $(\mathrm{n}=45)$ & 0.023 & $<0.001$ & 0.089 & $<0.001$ \\
\hline \multirow{6}{*}{ ID } & $0 \mathrm{kGy}$ & $1.4 \pm 0.5$ & $997 \pm 265$ & $41 \pm 80$ & $1039 \pm 265$ \\
\hline & $0.5 \mathrm{kGy}$ & $3 \pm 3$ & $1121 \pm 389$ & $20 \pm 12$ & $1144 \pm 391$ \\
\hline & $1 \mathrm{kGy}$ & $1.6 \pm 0.5$ & $1080 \pm 198$ & $27 \pm 19$ & $1109 \pm 204$ \\
\hline & $3 \mathrm{kGy}$ & $1.2 \pm 0.3$ & $1029 \pm 220$ & $21 \pm 9$ & $1052 \pm 221$ \\
\hline & $6 \mathrm{kGy}$ & $1.4 \pm 0.5$ & $1049 \pm 288$ & $21 \pm 9$ & $1072 \pm 291$ \\
\hline & $P$-value $(\mathrm{n}=27)$ & 0.001 & 0.518 & 0.298 & 0.611 \\
\hline $\mathrm{ST} \times \mathrm{ID}$ & $P$-value & 0.003 & 0.218 & $<0.001$ & 0.125 \\
\hline
\end{tabular}

Results are reported as mean value of each irradiation dose (ID) over the different storage times (ST) as well as mean value of all ST within each ID. Therefore, SD reflects values in those samples (under different ID or ST). In each column, different letters mean significant differences. 
Table 4. Composition in free sugars $(\mathrm{g} / 100 \mathrm{~g} \mathrm{dw})$ according with ID and ST (mean $\pm \mathrm{SD})$.

\begin{tabular}{|c|c|c|c|c|c|c|}
\hline & & Fructose & Glucose & Sucrose & Raffinose & Total sugars \\
\hline \multirow{4}{*}{ ST } & 0 days & $0.1 \pm 0.1$ & $0.1 \pm 0.1$ & $19 \pm 2 \mathrm{~b}$ & $0.1 \pm 0.1$ & $19 \pm 2 b$ \\
\hline & 30 days & $0.1 \pm 0.1$ & $0.1 \pm 0.1$ & $22 \pm 2 \mathrm{a}$ & nd & $23 \pm 2 \mathrm{a}$ \\
\hline & 60 days & $0.2 \pm 0.4$ & $0.2 \pm 0.4$ & $23 \pm 3 \mathrm{a}$ & nd & $23 \pm 3 \mathrm{a}$ \\
\hline & $P$-value $(\mathrm{n}=45)$ & 0.474 & 0.654 & 0.478 & 0.081 & 0.440 \\
\hline \multirow{6}{*}{ ID } & $0 \mathrm{kGy}$ & $0.2 \pm 0.4$ & $0.2 \pm 0.4$ & $22 \pm 3$ & $0.1 \pm 0.1$ & $22 \pm 4$ \\
\hline & $0.5 \mathrm{kGy}$ & $0.07 \pm 0.05$ & $0.1 \pm 0.1$ & $22 \pm 3$ & $0.1 \pm 0.1$ & $22 \pm 3$ \\
\hline & $1 \mathrm{kGy}$ & $0.2 \pm 0.3$ & $0.2 \pm 0.4$ & $21 \pm 2$ & $0.04 \pm 0.05$ & $21 \pm 2$ \\
\hline & 3 kGy & $0.1 \pm 0.1$ & $0.1 \pm 0.1$ & $21 \pm 3$ & $0.04 \pm 0.05$ & $21 \pm 3$ \\
\hline & 6 kGy & $0.2 \pm 0.2$ & $0.2 \pm 0.2$ & $22 \pm 3$ & $0.03 \pm 0.05$ & $22 \pm 3$ \\
\hline & $P$-value $(\mathrm{n}=27)$ & 0.092 & 0.103 & $<0.001$ & $<0.001$ & $<0.001$ \\
\hline $\mathrm{ID} \times \mathrm{ST}$ & $P$-value & 0.755 & 0.532 & 0.184 & 0.040 & 0.168 \\
\hline
\end{tabular}

nd- not detected. Results are reported as mean value of each irradiation dose (ID) over the different storage times (ST) as well as mean value of all ST within each ID. Therefore, SD reflects values in those samples (under different ID or ST). In each column, different letters mean significant differences. 
Table 5. Linear Discriminant Analysis parameters considering different grouping variables.

\begin{tabular}{|c|c|c|c|c|c|}
\hline \multirow{2}{*}{$\begin{array}{l}\text { Grouping } \\
\text { variable }\end{array}$} & \multirow{2}{*}{ Assayed variables } & \multicolumn{2}{|c|}{ Correctly classified cases $(\%)$} & \multirow{2}{*}{ Number of defined functions } & \multirow{2}{*}{ Selected variables } \\
\hline & & Original grouped & Cross-validated grouped & & \\
\hline $\mathrm{ST}$ & \multirow[t]{2}{*}{ All } & 96.7 & 96.7 & 2 & $\begin{array}{l}\text { C6:0, C10:0, C12:0, C18:2, C23:0, } \\
\text { fructose, raffinose, dry matter }\end{array}$ \\
\hline ID & & 36.7 & 36.7 & 1 & $\mathrm{C} 12: 0$ \\
\hline ST & \multirow{2}{*}{ Nutritional parameters } & 66.7 & 66.7 & 1 & Dry matter \\
\hline ID & & - & - & - & No variables were qualified \\
\hline ST & \multirow{2}{*}{ Fatty acids } & 80.0 & 76.7 & 2 & $\mathrm{C} 10: 0, \mathrm{C} 12: 0, \mathrm{C} 17: 0, \mathrm{C} 23: 0$ \\
\hline ID & & 36.7 & 36.7 & 1 & $\mathrm{C} 12: 0$ \\
\hline $\mathrm{ST}$ & \multirow{2}{*}{ Tocopherols } & 50.0 & 50.0 & 1 & $\gamma$-tocopherol \\
\hline ID & & 26.7 & 26.7 & 1 & $\gamma$-tocopherol \\
\hline ST & \multirow{2}{*}{ Sugars } & 64.4 & 64.4 & 1 & Raffinose \\
\hline ID & & - & - & - & No variables were qualified \\
\hline
\end{tabular}




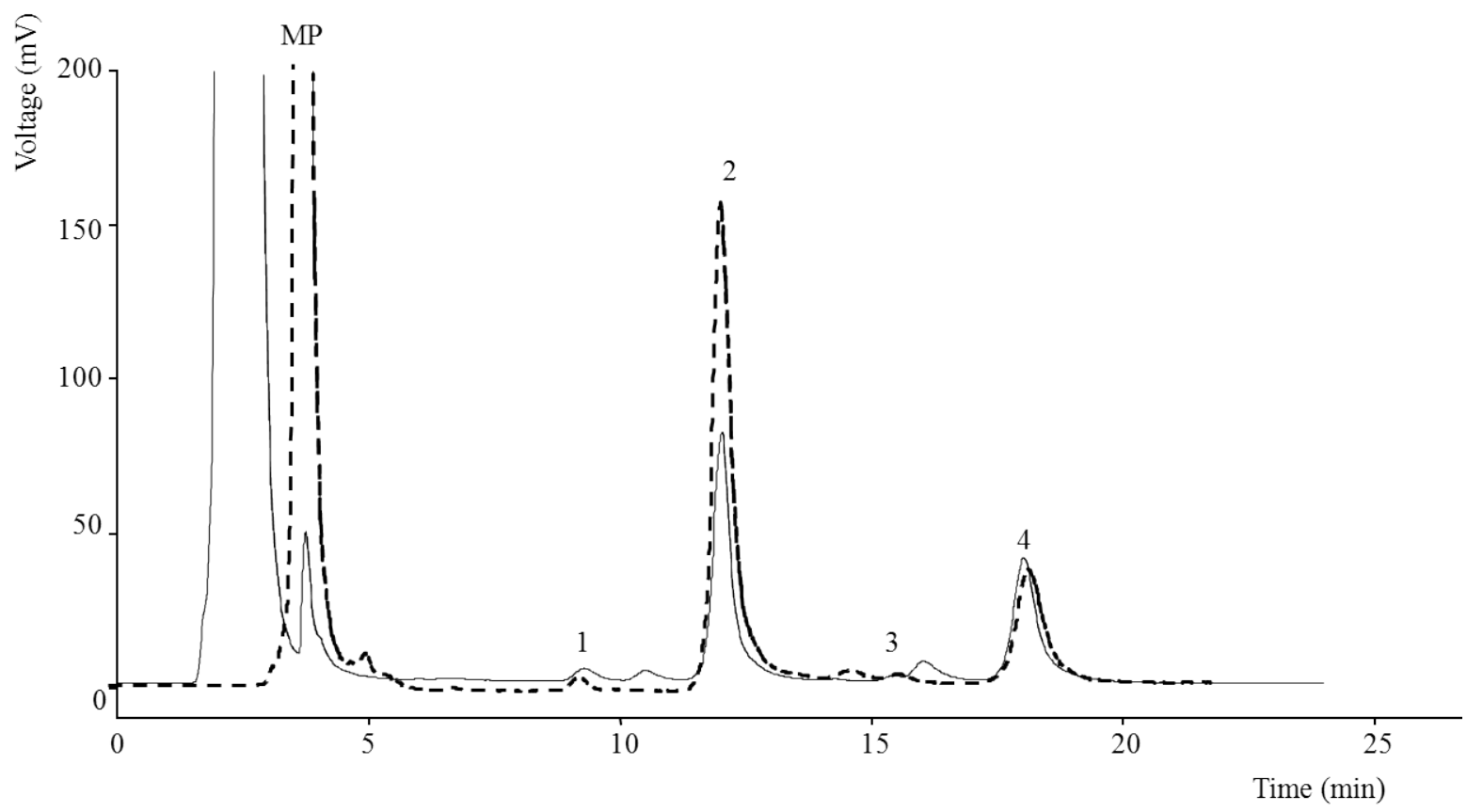

A

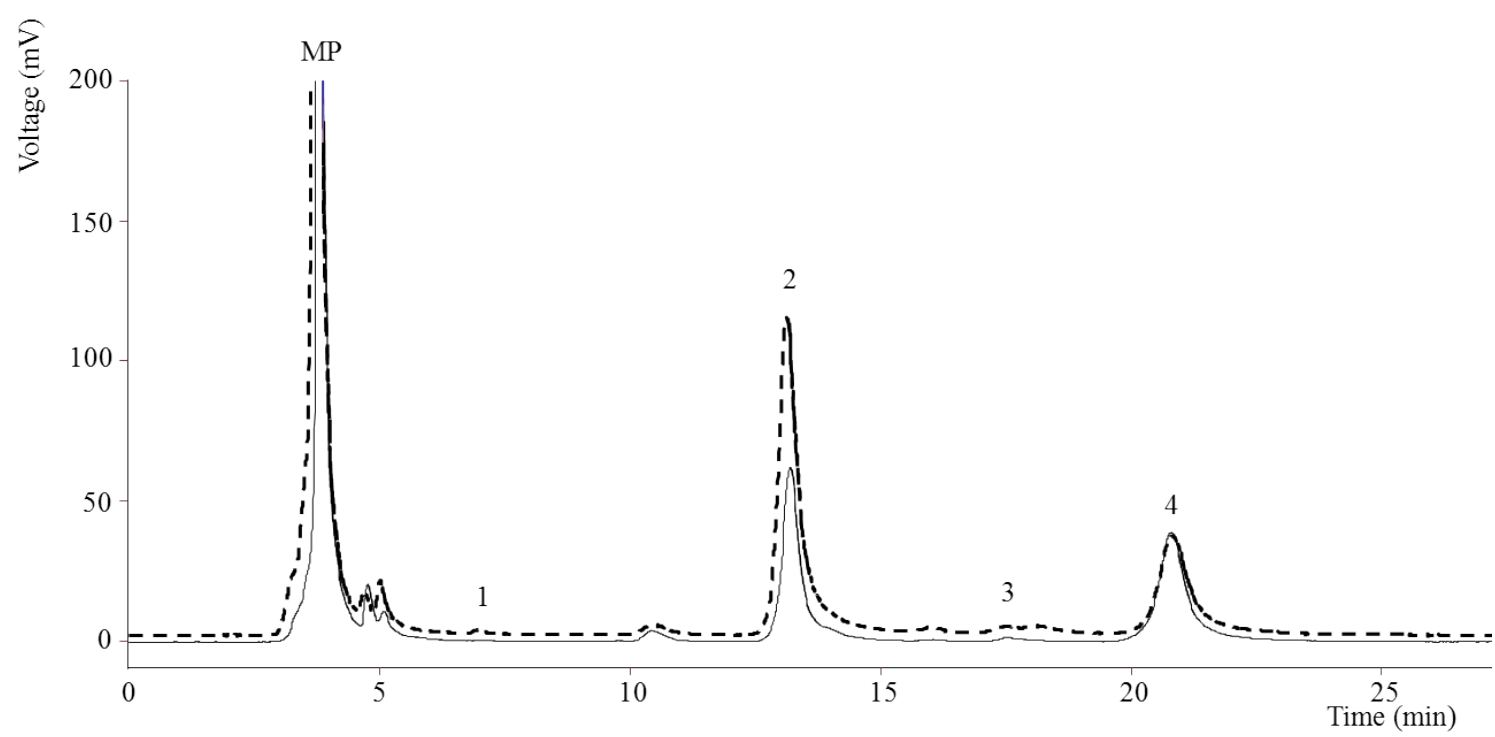

B

Figure 1. Tocopherols profile of A) non-irradiated samples, after 0 days (- - -) and 60 days (-) of storage; B) non-irradiated sample (- - -) and sample irradiated at $6 \mathrm{kGy}$ (-) after 60 days of storage. MP - Mobile phase; 1 - $\alpha$-Tocopherol; 2- $\gamma$ - tocopherol; 3 $\delta$-tocopherol; and 4-tocol (IS). 


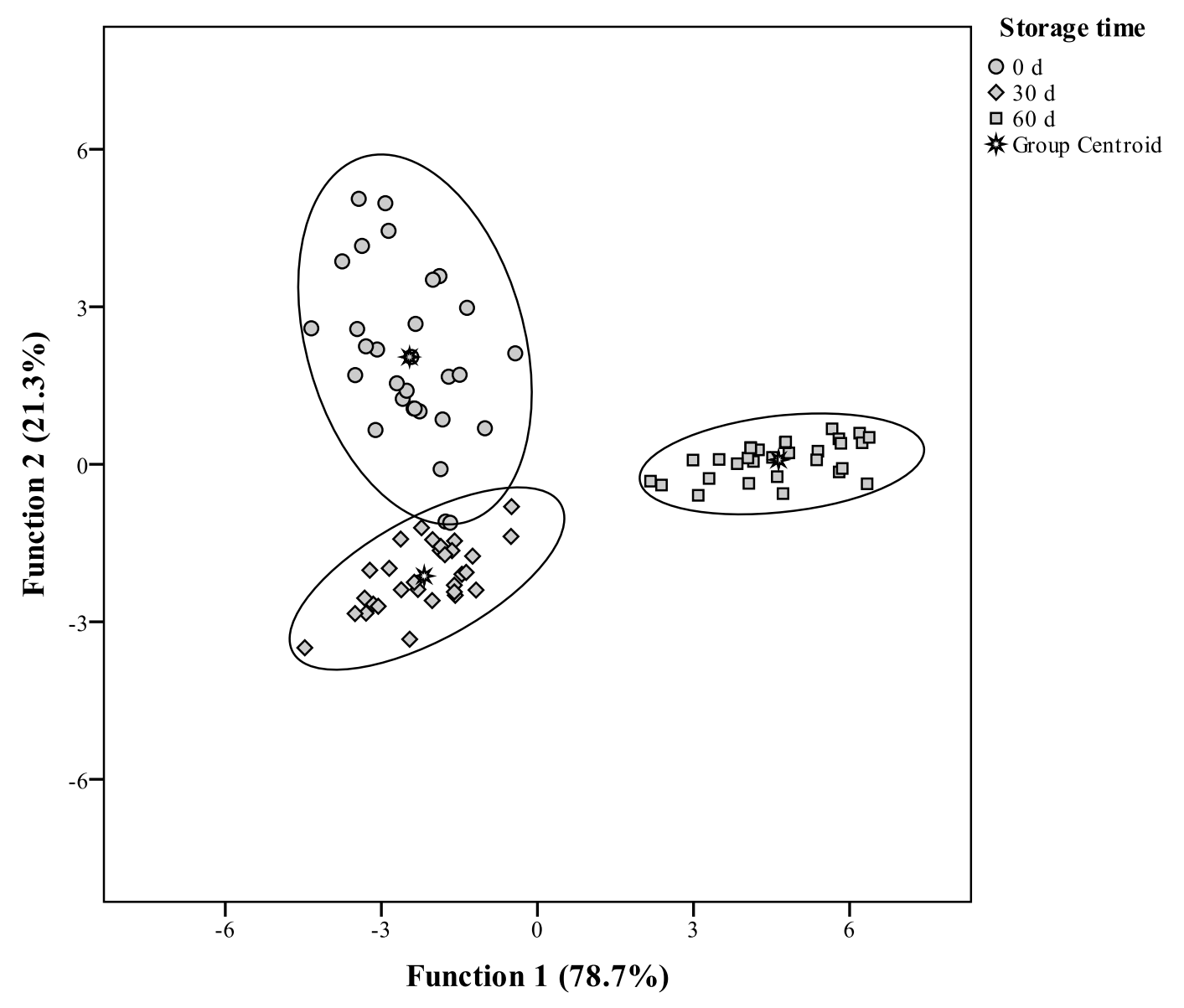

Figure 2. Discriminant scores scatter plot of the canonical functions defined for all assayed parameters results. 
Effects of electron beam radiation on nutritional parameters of Portuguese

\section{chestnuts (Castanea sativa Mill.)}

Márcio Carocho, João C.M. Barreira, Amilcar L. Antonio, Albino Bento, Iwona Kaluska, Isabel C.F.R. Ferreira

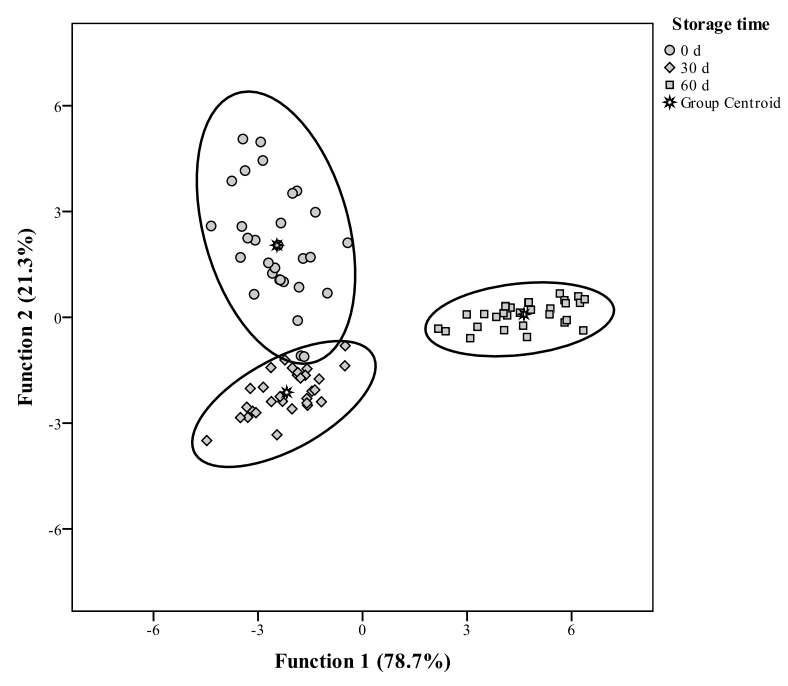

